\title{
Discurso de agradecimiento
}

\author{
Antonio Jesús Diez Quesada
}

Distinguidas autoridades del ITAM, compañeros profesores, amable público que nos acompaña el día de hoy:

Es para mí un honor encontrarme en esta ceremonia, designado Profesor Emérito en compañía de dos profesores de excelencia por los cuales siento profunda admiración. El ITAM, desde que comencé a dar algún curso en el año de 1978, representa para mí un lugar ideal en el cual se encarnan los valores más altos de la cultura humana, como son el rigor intelectual y la defensa de los valores más apreciados de la libertad, la democracia, la tolerancia y la apertura hacia un futuro más promisorio para la humanidad.

Nos encontramos en una situación especialmente difícil en el transcurrir de la cultura humana. Desde sus inicios en el Paleolítico, la actividad humana ha avanzado hacia momentos de mayor lucidez y desarrollo. Hubo un tiempo en la historia al que se denomina Época Axial, o sea, un eje que parte y diferencia el desarrollo del espíritu humano en dos etapas. Por algún motivo desconocido, simultáneamente y muchas veces sin contacto, en diferentes lugares geográficos ocurrió una transformación del espíritu humano de la cual somos en gran parte herederos. En esta era nació en Grecia la filosofía que separó mythos y logos e inició la reflexión racional del género humano. Se pusieron los cimientos de la ciencia, de la lógica y de una forma racional de concebir al mundo y su devenir. Por otro lado, en Israel fue la época de los grandes profetas, que dieron un profundo signo al pueblo elegido. Simultáneamente, en Persia o Irán vivió Zaratustra o Zoroastro, cuya religión influyó poderosamente tanto en los hebreos como en la India. En la propia India, fue una época de gran esplendor filosófico en la que vivieron Siddharta Gautama el Buda y Mahavira, y empezaron a compilarse los 
Upanishads, que son la gran reflexión y profundización sobre los Vedas. También se produjo la aparición un tanto extraña en un país profundamente religioso como la India de un pensador ateo: Carvaka. En China, por otro lado, se pusieron los fundamentos de su filosofía clásica, que extendieron su influencia a Corea, Japón y otros lugares del Lejano Oriente. Fue la época de Confucio, que hoy en día está considerado en China la figura más importante de su cultura. Por eso el Instituto Cultural Chino se denomina "Instituto Confucio". También fue el momento de los grandes pensadores taoístas, como Lao-Tse, Chuang-Tse y Liu-Tse, así como de la escuela de la interacción entre el ying y el yang.

Esta radical transformación que sufrió el espíritu humano afectó a nuestra cultura de manera tan profunda que inclusive hoy seguimos en gran parte las directrices que esos pensadores nos trazaron. Llevaron la cultura humana a otro nivel de reflexión, de profundidad y de desarrollo, y se convirtieron de alguna manera en maestros de la humanidad. Prácticamente ningún pensamiento actual es ajeno a sus propuestas y de alguna forma siempre estamos haciendo referencia a ellos como autores de los principios que nos siguen rigiendo.

Esos personajes fundaron las primeras instituciones de educación superior, como la Academia y el Liceo, la Universidad budista Nalanda en India, o las Escuelas Confucianas, que dieron origen en la Edad Media a las universidades musulmanas como al Azhar de Egipto y las cristianas en Europa, hasta llegar a nuestra época, que es la de mayor amplitud y despliegue de la globalización que se haya conocido.

Hoy, por primera vez en la historia de la humanidad, los habitantes de todos los continentes del planeta Tierra estamos en contacto permanente y simultáneo gracias a los nuevos medios de transporte y comunicación. Por primera vez los hombres empezamos a tener un espíritu profundamente universal. Una de las tareas que se ha acabado es la del viajero que nos cuenta historias de lugares remotos e ignotos para asombro de sus lectores. Los jóvenes actuales son profundamente globales y tienen una idea bastante clara de las costumbres, fisonomías y rasgos peculiares de otras zonas del mundo. Las ciudades en el transcurrir de nuestra vida han cambiado. Hoy prima en gran parte de Europa y América el multiculturalismo, y no solo como intercambio comercial y cívico, sino también cultural. Algo muy importante en estas circunstancias es 
evitar los guetos, evitar que las personas se separen en virtud de su religión, etnia y otras características. La convivencia debe ser de apertura hacia el otro, de un convivir tolerante, abierto, de aprendizaje y de enriquecimiento mutuos, lo cual exige una ética mínima que propicie la convivencia entre personas de diferentes ascendencias, pero que tengan elementos grandes y profundos comunes. Las sociedades abiertas, como por ejemplo las europeas, no pueden ser tolerantes con el intolerante. En nuestro mundo se tienen que respetar los valores cívicos y morales que propicien una convivencia armoniosa y fecunda entre diversos grupos humanos. Los grandes enemigos de la nueva sociedad democrática y libre actualmente están acumulando mucho poder y se expanden los fundamentalismos, el populismo, el racismo, la xenofobia, y hemos de luchar contra estos males propugnando una cultura abierta a los valores universales y a las prácticas democráticas. Tenemos que aprender a vivir juntos. El gran político y pedagogo Jacques Delors nos propone como tarea inexcusable de la educación cuatro grandes pilares: aprender a vivir juntos, aprender a aprender, aprender a hacer y aprender a ser. Con estos principios se pretende que las nuevas generaciones de niños y jóvenes sepan convivir con sus compañeros y vecinos en un ambiente de respeto y ayuda mutua.

Quizá la concreción más eficaz de estos valores se da en nuestros días en la defensa y la promoción mundial de los derechos humanos, que tienen un valor universal y deben ser respetados por todos los países, independientemente de su cultura. Los derechos humanos se fundan en aspectos o cualidades ínsitas en el ser humano, como su dignidad. La dignidad es la base del respeto más profundo hacia cualquier ser humano. A esta cultura le falta mucho para que se expanda lo suficiente, pero su concientización ha avanzado enormemente en los últimos tiempos.

Seguramente el pensador mexicano más universal, Octavio Paz, fue uno de los pioneros que visualizó a este nuevo ser humano, y en sus grandes obras, como por ejemplo El laberinto de la soledad o Vislumbres de la India, da cuenta de qué características debe de tener este nuevo hombre para el siglo XXI. Se da cuenta de que los hombres actuales de alguna manera estamos hermanados por cierta indigencia de carácter ontológico, pero a la vez tenemos que superar axiológicamente esta menesterosa situación. Sus largos años de experiencia como embajador 
de México en la India y sus largas estadías en el extranjero le dieron a Paz una visión acertada y clara acerca del rumbo que deberían tomar los hombres en la nueva situación.

Los grandes maestros de la literatura universal son quienes aúnan lo más local, lo más humano y, por ello mismo, lo más común a todos los hombres. El Quijote es profundamente español y a la vez mundial. En estos momentos, es uno de los clásicos más leídos en China. Para los alemanes, la mejor encarnación de su espíritu es Goethe y los lectores de todo el mundo disfrutamos con los libros del premio Nobel nigeriano Wole Soyinka, del maravilloso egipcio Naguib Mahfuz y del extraordinario misticismo y belleza bucólica de las montañas chinas del también premio Nobel Gao Xingjian. Por supuesto, los latinoamericanos como Borges y Rulfo son insuperables. Ellos nos muestran la profundidad del alma, su belleza, el espíritu humano en sus diferentes manifestaciones y versatilidad, las relaciones de la imaginación con la fantasía y la realidad, y fomentan la creatividad que los hombres necesitamos para superar las dificultades del nuevo siglo.

El siglo XXI se enfrenta a nuevos retos: el peligro de una guerra nuclear, el cambio climático, la informatización, la ingeniería genética, una situación parecida a la que privaba antes de Alexander Fleming, en la que los antibióticos dejan de ser eficaces y la humanidad enfrenta nuevamente epidemias y pestes que pueden causar miles de muertos y ante las cuales estamos inermes. Ello nos puede conducir a un mundo poshumano; de hecho, ya en este momento grandes decisiones de los mercados financieros son tomadas por algoritmos y es posible que en un futuro próximo la inteligencia artificial plantee retos muy importantes al concepto de inteligibilidad humana. Por otro lado, el hombre podría cambiar por primera vez su naturaleza mediante la ingeniería genética. Como dice un filósofo catalán: antes, el automóvil en el cual metafóricamente se transporta la humanidad era conducido por Dios. Entonces las gentes se preguntaban: “¿a dónde vamos?”, y se contestaban: “a donde Dios nos quiera llevar", y se quedaban tranquilas. Luego, con la aparición de agnósticos y ateos, la naturaleza se puso al volante y las personas se preguntaban: “¿a dónde vamos?”, “donde la Naturaleza dicte". Pero en este momento, quien se pone al volante es el Hombre y nos dan miedo las decisiones que tome, porque se abre una incógnita y la humanidad puede tomar derroteros absolutamente desconocidos. 
Estos grandes retos tienen que ser contestados desde la educación. Una educación como la que imparte el ITAM, que luche por los valores de una sociedad libre, democrática y abierta hacia un futuro mejor para México y el mundo. Para mí es un orgullo poder participar en el esfuerzo de una gran institución tan digna y admirable como es el ITAM. Muchas gracias. 